\title{
ATIVIDADE DE ÓLEOS ESSENCIAIS DAS ESPÉCIES \\ LIPPIA INSIGNIS MOLDENKE E LIPPIA ORIGANOIDES KUNTH. NO \\ CONTROLE DE CARRAPATOS DE BOVINOS RHIPICEPHALUS \\ (BOOPHILUS) MICROPLUS
}

\author{
$\underline{\text { Arlian Vercosa da Silva Filho }}{ }^{1}$; Lenaldo Muniz de Oliveira ${ }^{2}$ Angélica Maria Lucchese $^{3}$; Mariana Borges \\ Botura $^{4}$ \\ Bolsista PIBIC/CNPq, Graduando em Agronomia, Universidade Estadual de Feira de Santana, e-mail: \\ agronomia.vercosa@hotmail.br \\ 2. Orientador, Departamento de ciências biológicas, Universidade Estadual de Feira de Santana, e-mail: \\ lenaldo.uefs@gmail.com \\ 3. Co-orientadora, Departamento de Exatas, Universidade Estadual de Feira de Santana, e-mail: \\ angelica.lucchese@gmail.com \\ 4. Co-orientadora, Departamento de saúde, Universidade Estadual de Feira de Santana, e-mail: \\ mbbotura@hotmail.com
}

PALAVRAS-CHAVE: Verbenaceae; Controle biológico; Biopesticida; Carrapato.

\section{INTRODUÇÃO}

A sanidade é caracterizada como um dos pilares fundamentais para produtividade de um rebanho bovino, e um dos principais problemas sanitários está relacionado à infestação por parasitas, sendo o carrapato o que mais traz problemas e atua como limitante no sucesso das criações (OLIVEIRA-SIQUEIRA, 2001).

O Rhipicephalus (Boophilus) microplus (carrapato-do-boi) é o mais importante ectoparasita dos rebanhos bovinos, sendo um parasito que apresenta facilidade de multiplicação nas condições climáticas brasileiras. Este carrapato alimenta-se de sangue, então provoca anemia, grande desconforto, perda de peso e redução na produção de leite e carne dos animais, desvalorização do couro, além de ser transmissor da doença conhecida com Tristeza Parasitária Bovina (FURLONG, 2005)

A busca por um modelo alternativo ou complementar, repercutiu no interesse pelas "terapias alternativas", destacando-se a utilização de óleos essenciais e extratos de plantas. Dentre as várias espécies botânicas que vem demonstrando potencial para uso no controle de ectoparasitas destaca-se o gênero Lippia, onde vários tipos de extratos e óleos essenciais vêm sendo amplamente testados por seu potencial antimicrobiano e antiparasitário em diferentes ensaios in vitro e in vivo (SOARES; TAVARES-DIAS, 2013).

O objetivo desse trabalho foi avaliar a eficácia do óleo essencial das espécies Lippia origanoides Kunth e Lippia insignis Moldenke no controle de carrapatos de bovinos Rhipicephalus (boophilus) microplus.

\section{METODOLOGIA}

a) Obtenção dos óleos essenciais

$\mathrm{O}$ material vegetal (folhas) foi colocado em estufa de ar circulante à $40^{\circ} \mathrm{C}$ e posteriormente moído em moinho de facas. A extração dos óleos essenciais foi realizada com o aparelho de destilação tipo Clevenger, utilizando-se $100 \mathrm{mg}$ de massa seca. O tempo de destilação foi de $3 \mathrm{~h}$. Após a destilação, o óleo juntamente com a água foi recolhido em um funil de separação, adicionando-se $3 \mathrm{~mL}$ de diclorometano, por três vezes, e sulfato de sódio anidro para separação da água residual. Finalmente, o filtrado foi colocado em rota evaporador para evaporar o diclorometano por $24 \mathrm{~h}$.

b) Coleta e transporte dos carrapatos 
As coletas foram realizadas em bovinos infestados naturalmente que se encontravam em propriedades parceiras previamente cadastradas no município de Feira de Santana e região. Com auxílio de luvas e sem qualquer resíduo de produto químico, foi retirado do corpo dos bovinos, fêmeas ingurgitadas com comprimento superior a 8 $\mathrm{mm}$. Em seguida os carrapatos foram acondicionados em um recipiente limpo (pote de plástico sem resíduos de produtos químicos), com orifícios para entrada de ar e papel umedecido com água forrando o fundo, mantendo assim o recipiente em um ambiente fresco até o momento da entrega no laboratório. Os carrapatos foram acondicionados em local arejado no laboratório de toxicologia da UEFS.

\section{c) Avaliação do potencial carrapaticida in vitro}

A avaliação da atividade biológica foi realizada no Laboratório de Toxicologia, localizado no campus da UEFS. Foi avaliado o efeito de diferentes concentrações do óleo essencial de Lippia origanoides $(6,25 ; 12,5 ; 25 \mathrm{mg} / \mathrm{ml})$ e uma concentraçãodo óleo essencial de L. insignis $(24 \mathrm{mg} / \mathrm{ml})$. Como controle negativo foi utilizado o tratamento sem óleo, apenas o tween a 5\% (utilizado para solubilizar o óleo essencial) e como controle positivo o fipronil (carrapaticida comercial de maior uso atual na concentração recomendada pelo fabricante).

As fêmeas ingurgitadas foram colocadas aleatoriamente em grupos de $10 \mathrm{em}$ placas de petri com pesos iguais para cada tratamento, sendo utilizado três tratamentos para cada concentração. Os grupos foram emergidos durante 5 minutos na solução com óleo e logo após a imersão as fêmeas foram coladas na placa de petri, (DRUMMOND et al., 1973). Após o banho, as fêmeas foram mantidas sob condições ideais de temperatura e umidade onde, acompanhando-se o efeito do tratamento na sobrevivência e capacidade de produção de ovos e larvas (DRUMMOND, 1973).

O delineamento experimental utilizado foi o inteiramente casualizado, com três repetições (placas de Petri), com 10 fêmeas por repetição. O cálculo da eficácia do produto (EP) foi realizado a partir de fórmulas matemáticas abaixo descritas (Drummond et al., 1973):

$\mathrm{RE}=$ peso dos ovos $\mathrm{x} \%$ de eclosão $\mathrm{x} 20.000^{*} /$ peso das fêmeas

$\mathrm{RE}=$ Reprodução estimada * Constante que indica o número de ovos presentes em $1 \mathrm{~g}$ de postura produto .

$\mathrm{EP}=\mathrm{RE}($ controle $)-\mathrm{RE}$ (tratado) $\mathrm{x} 100 / \mathrm{RE}$ (controle) $\mathrm{EP}=$ Eficácia do

O teste de imersão de larvas foi realizado com três concentrações de óleos da espécie Lippia insignis $(6,25 ; 12,5$ e $24 \mathrm{mg} / \mathrm{ml})$. Com seringas cortadas nas pontas, foram adicionados os grupos de larvas e vedado com tecido voil com auxílio de elástico. Para cada concentração foram testadas quatro repetições, exceto o controle que teve apenas três. Esse foi realizado com tween 80 a 2,5\%. Cada grupo de larvas foi imergido nas diluições dos óleos essenciais por cinco minutos, sendo, em seguida, colocada em contato com papel absorvente para eliminar o líquido excedente. As seringas foram postas na galeria por 24 horas e decorrido esse tempo, procedeu-se a contagem das larvas vivas e mortas com auxílio de uma fonte luminosa.

\section{RESULTADOS E DISCUSSÃO}

A porcentagem de eclodibilidade dos ovos na concentração de $25 \mathrm{mg} / \mathrm{ml}$ no óleo essencial de L. origanoides foi de 31,67\%, havendo diferença significativa quando comparado ao controle negativo. Para as demais concentrações $(12,5$ e 6,25) não foram detectadas diferenças significativas em relação ao controle (Figura 1). A eficiência do óleo essencial de L. origanoides na concentração de $25 \mathrm{mg} / \mathrm{ml}$ foi de $54,57 \%$, em 12,5 
$\mathrm{mg} / \mathrm{ml}$ foi de $8,16 \%$ e na menor concentração $6,25 \mathrm{mg} / \mathrm{ml}$ foi de $5,68 \%$. Já o óleo essencial de L. insignis na concentração de $24 \mathrm{mg} / \mathrm{ml}$ promoveu uma média de eclodibilidade de $80 \%$, quando comparado ao controle negativo, não havendo diferenças significativas e a eficiência do produto foi de 3,68\%. Para o teste de larvas com óleo essencial de L. insignis na concentração de $24 \mathrm{mg} / \mathrm{ml}$, houve $100 \%$ de letalidade. $\mathrm{Na}$ concentração de $12,5 \mathrm{mg} / \mathrm{ml}$ houve uma média de $54,5 \%$ de ação larvicida, e na menor concentração testada $(6,25 \mathrm{mg} / \mathrm{ml})$ o índice de mortalidade das larvas foi de $33,38 \%$ como mostra a figura 2. Na análise estatística dos resultados, todas as concentrações promoveram diferenças significativas em um intervalo de confiança de $99 \%$, quando comparadas ao controle negativo.

(A)

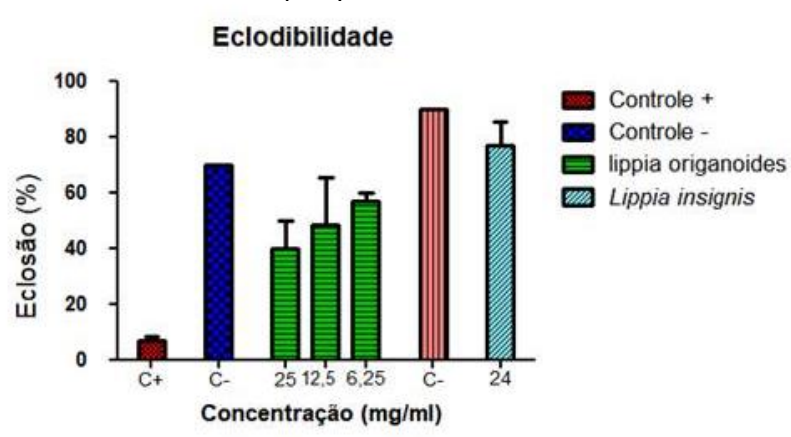

(B)

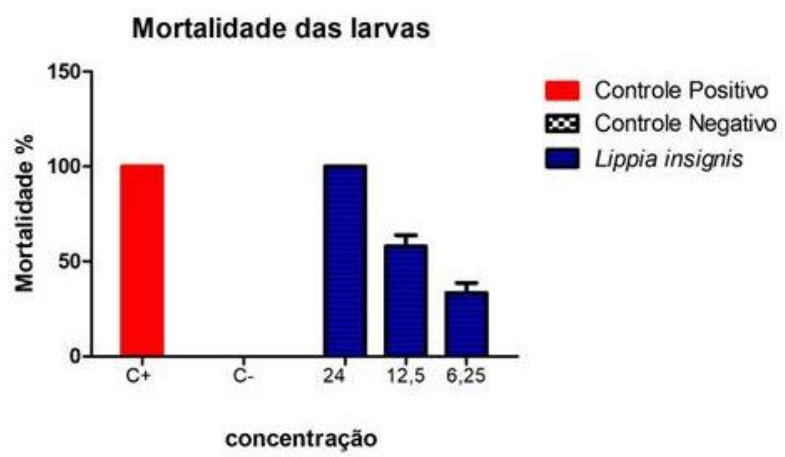

(A). Gráfico com o percentual de eclosão dos ovos de carrapatos de bovinos Rhipicephalus (boophilus) microplus nas diferentes concentrações de óleo essencial de $L$. origanoides e na única concentração de $L$. insignis. (B). Gráfico esboçando a eficiência do óleo de $L$. insignis na letalidade das larvas de carrapatos de bovinos Rhipicephalus (boophilus) microplus.

Resultados semelhantes foram obtidos por Lima (2014) testando o efeito do óleo essencial de L. alba, com $100 \%$ de atividade contra larvas de R. Microplus. CHUNGSAMARNYART \& JIWAJINDA (1992) comprovaram a ação acaricida e larvicida do óleo de citronela (Cymbopogon nardus L. Rendle) sobre fêmeas de $R$. Microplus em três concentrações $(12,5 ; 8,3$ e 7,1\%) diluído em etanol, obtendo, respectivamente 95,7; 92,7 e 58,1\% de mortalidade. Esses resultados são superiores aos do presente trabalho no teste das teleóginas, porém quando comparados ao teste de larvas, são inferiores, uma vez que a maior concentração usada no presente trabalho, obteve-se $100 \%$ de letalidade contra as larvas. . Olivo et al. (2008) mostram que as concentrações do óleo de citronela $(100,50,25,10$ e 1\%) proporcionaram maior inibição de postura de ovos pelas fêmeas ingurgitada, todas com mais de $80 \%$ de eficácia do produto. Os resultados obtidos no trabalho de Farias (2007) para eficácia "in vitro" do óleo da Carapa guianensis sobre B. microplus foram $100 \%$ para todas as diluições testadas $(100,50,30,25$ e 10\%).

Segundo Queiroz (2014) através de resultados da cromatografia gasosa do óleo essencial de Lippia origanoides foi verificado que o timol é o principal agente presente no óleo extraído dessa mesma planta, chegando a quase 50\%. Castro (2005) demonstrou que o óleo essencial de L. insignis possui como constituinte majoritário o limoneno

\section{Conclusão}

Os óleos essenciais das espécies L. origanoides e Lippia insignis apresentam potencial para produção de biocarrapaticidas, com ação sobre a eclodibilidade dos ovos e mortalidade das larvas, respectivamente. 


\section{REFERÊNCIAS}

DRUMMOND, R. O.; ERNST, S. E.; TREVINO, J. L.; GLADNEY, W. J.; GRAHAM, O. H. Boophilus annulatus and Boophilus microplus: laboratory tests of insecticides. Journal of Economic Entomology, Lanham, v. 66, n. 1, p. 130-133, 1973.

FURLONG, J. Carrapato: problema e soluções. Embrapa Gado de Leite; Juíz de Fora, 2005. Disponível em: http://docplayer.com.br/6894428-.html\#show_full_text Acesso em: 17 Mar. 2017.

LIMA, Aldilena da Silva. Atividade repelente e carrapaticida de extratos e óleos essenciais de plantas sobre o carrapato bovino Rhipicephalus microplus. ChapadinhaMA 2014. Disseraação de mestrado.

MONTEIRO, C. M. O.; DAEMON, E.; SILVA, A. M. R.; MATURANO, R. \& AMARAL, C. 2010. Acaricide and ovicide activities of thymol on engorged females and eggs of Rhipicephalus (Boophilus) microplus (Acari: Ixodidae). Parasitology Research, 106: 615-619.

OlIVEIRA-SEQUEIRA, T. C. G.; AMARANTE, A. F. T. Parasitologia Animal: Animais de Produção. Rio de Janeiro, Editora EPUB, 2001. 195 p.

SOARES, B. V.; TAVARES-DIAS, M. Espécies de Lippia (Verbenaceae), seu potencial bioativo e importância na medicina veterinária e aquicultura. Biota Amazônia, Macapá, v. 3, n. 1, p. 109-123, 2013

CHUNGSAMARNYART, N.; JIWAJINDA, S. Acaricidal activity of volatile oil from lemon and citronella grasses on tropical cattle ticks. Kasetsart Journal, v.26, p.46-51, 1992.

OLIVO, Clair Jorge et.al. Óleo de citronela no controle do carrapato de bovinos. Ciência Rural, Santa Maria, v.38, n.2, p.406-410, mar-abr, 2008.

FARIAS, M.P.O. et al. Eficácia in vitro do óleo da Carapa guianensis Aubl. (andiroba) no controle de Boophilus microplus (Acari: Ixodidae). Rev. Bras. Pl. Med., Botucatu, v.9, n.4, p.68-71, 2007.

CASTRO, Henrique Guilhon; FERREIRA, Francisco Afonso; SILVA, Derly José Henrique; MOSQUIM, Paulo Roberto. Contribuição ao estudo das plantas medicinais metabólitos secundários. $2^{\mathrm{a}}$. Edição. Editora Visconde do Rio Branco, Viçosa, 2004. 113 p.

SOUZA, Antonio P. de. et al. PROPOSTA PARA TESTE CARRAPATICIDA POR IMERSÃO DE LARVAS DE Rhipicephalus (Boophilus) microplus: AVALIAÇÃO EM CIPERMETRINA E AMITRAZ. Rev. Bras. Parasitol. Vet., 17, 4, 242-245 (2008)

VIEIRA, Roberto Fontes; SALIMENA, Fatima Regina Gonçalves; SILVA. Dijalma Barbosa da. Espécies Nativas da Flora Brasileira de Valor Econômico Atual ou Potencial. Brasilia 2016 